\title{
Inferior alveolar nerve damage after extrusion of an endodontic sealer into the mandibular canal: a case report
}

\author{
Zeliha Yılmaz, Emel Uzunoğlu, Özge Erdoğan \\ Department of Endodontics, Hacettepe University Faculty of Dentistry, Ankara, Turkey
}

\begin{abstract}
The aim of this case report was to discuss the consequences and treatment options of inferior alveolar nerve damage after the overextension of an endodontic sealer into the mandibular canal. A 33-year-old female patient was referred to the clinic of endodontics with persistent numbness around her left commissura as a consequence of her initial endodontic treatment of a lower left first molar. The patient's complaints started to occur after the anesthesia has worn off. An endodontic sealer was extruded and spread into the mandibular canal, which caused anesthesia, paresthesia and tingling sensation around the left part of lower lip. Performing an interdisciplinary framework with the department of oral surgery, it was decided to monitor the patient regularly without any surgical intervention in order not to cause more trauma to the inferior alveolar nerve and not to jeopardize the present health status of the patient. Although damage to the inferior alveolar nerve is a relatively rare complication in dental practice, longlasting consequences of such a complication stress the significance of showing absolute attention and care during all endodontic.
\end{abstract}

Keywords: Inferior alveolar nerve; paresthesia; root canal sealer.

$\mathrm{T}$ The essential steps for successful endodontic treatment consist of elimination of all diseased pulp and dentin tissues, adequate chemomechanical preparation and filling of the root canal system hermetically. ${ }^{[1]}$ Moreover, it is crucial that root canal obturation has to be limited within root canal system. Minor apical foramen or minor apical constriction is known to be situated $0.5-1.5 \mathrm{~mm}$ coronally to the apical foramen and endodontic treatment is suggested to be finished in this constricted region. ${ }^{[2]} \mathrm{A}$ small wounded surface is created when endodontic procedures are restricted within the root canal system, as a result extrusion of the toxic constitutes of obturation materials beyond apical foramen is prevented. What is more, with the activation of the immune system, healing is elicited rapidly. On the other hand, accidental extrusion of canal ingredients may result in postoperative pain and delayed healing. ${ }^{[3-5]}$

Miscalculation of working length, procedural errors, anatomical and morphological variations may cause apical extrusion even to the anatomical landmarks such as maxillary sinus and mandibular canal. Direct contact of the nerve with extruded materials may result in some abnormal sensations such as anesthesia, paresthesia, hypoasthesia and dysesthesia. ${ }^{[3,6-10]}$

The present case report discusses the causes and treatment options of inferior alveolar nerve damage following the overextension of an endodontic sealer into the mandibular canal.

Correspondence: Dr. Emel Uzunoğlu. Hacettepe Üniversitesi Diş Hekimliği Fakültesi,

Endodonti Anabilim Dalı, Ankara, Turkey.

Tel: +90 312 - 3052260 e-mail: emel_dt@hotmail.com

Submitted: February 09, 2016 Accepted: April 05, 2016 


\section{Case report}

A 33-year-old female patient was referred to department of endodontics in March 2014. Her dental anamnesis revealed a root canal treatment for her lower left first molar in a private clinic 13 months ago. The numbness around her left commissura had begun right after the anesthetic worn off. In the panoramic radiograph taken the next day following treatment (Figure la), a radiopaque root canal obturation paste was observed in the mandibular canal. Her dentist prescribed Vitamin B12 for two months; however, the paresthesia didn't improve.

The Medical history revealed, chemotherapy and radiotherapy following surgery due to breast cancer in 2010. She was on Tamoxifen $10 \mathrm{mg}$ twice a day since then.

No signs of inflammation were detected during clinical examination. The patient reported numbness and tingling sensation around her left commissura, which recovered very little over time. Light touch, thermal and mechanical tests were negative around the lower left lip and left commissura, while lingual tissues responded within normal limits. These findings suggested that the affected region was around the inferior alveolar nerve especially around its distal end.

Radiopacity was observed in the mandibular canal, between the apices of lower left second premolar and the mesial root of lower left second molar taken right after the treatment upon the symptoms. A cone-beam computed tomographic (CBCT) imaging (Planmeca ProMax 3D Max; Planmeca, Helsinki, Finland) (Figure 2) was asked as well as new panoramic and periapical radiographs (Figure $\mathrm{lb}$ and $\mathrm{c}$ ). No visual changes were observed since the previous radiographs and the roots of the lower left first molar were in direct contact with the mandibular canal.

The results were discussed within a multidisciplinary approach with the department of oral surgery. Surgical intervention in order to clean the mandibular canal was also discussed with the patient. Taking into consideration of both the oral surgeons' approach and the patient's own opinion, it was decided to monitor the patient every 6 month in order to monitor any change; whether it would be improvement or deterioration. However, no changes were expected, since, there had been no alternations since the extrusion had occurred. On May 2015, the patient's 1-year recall revealed that her clinical symptoms were persistent (Figure ld). On radiographic examination, no change was observed.

\section{Discussion}

Any damage to the inferior alveolar nerve due to endodontic treatment is relatively rare. A recent PubMed database search with the keyword combination "endodontic and paresthesia" was revealed 70 articles since 1976. Careful examination showed that the numbers of articles regarding paresthesia were 61 (review and/or case reports). Even though these complications are rare, they are as significant as other complications that clinicians face during root canal treatment especially concerning their possible irreversible consequences.

The aim of presenting this case is to stress the importance of taking necessary precautions during root canal treatment. Therefore, examination of the initial dental radiograph is significant especially for those, which are in close proximity with important anatomical structures such as mandibular canal and maxillary sinus. ${ }^{[1,12]}$ More careful analysis and working length determination may be necessary for mandibular first molars where variations occur more frequently compared to mandibular second and third molars ${ }^{[13]}$ as in this case report.

Mandibular canal is surrounded by dense hyper-mineralized bone. Yet, it can be perforated during root canal preparation. ${ }^{[11]}$ Tilotta-Yasukawa et al. ${ }^{[13]}$ discuss that in the posterior region of mandible, bone is not always very dense because it has a greater amount of trabecular bone, which may facilitate the penetration and spreading of foreign materials to the mandibular canal. In addition, a dense cortical bone is not always present around the mandibular canal. ${ }^{[14,15]}$ Thus, apically extruded debri can directly contact the inferior alveolar nerve and may induce chemical and biological mechanisms. To avoid this, combining the initial radiograph and the apex locator results, during working length determination, preparing a solid apical stop, strict adherence to the working length during obturation as well as chemomechanic preparation are essential preventive measures. ${ }^{[16]}$
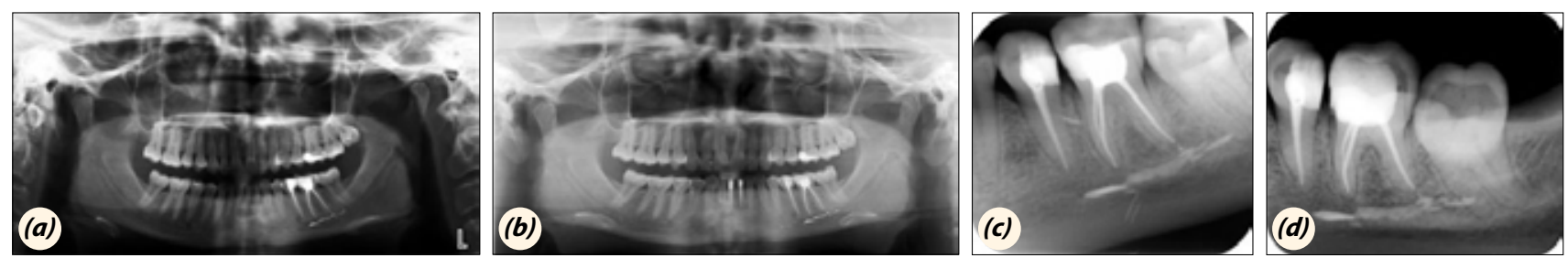

Fig. 1. (a) Panaromic radiograph after initial treatment (y. 2013). (b) Panaromic radiograph after patient's referral (y. 2014). (c) Periapical radiograph after patient's referral (y. 2014). (d) Periapical radiograph after 1-year recall (y. 2015). 

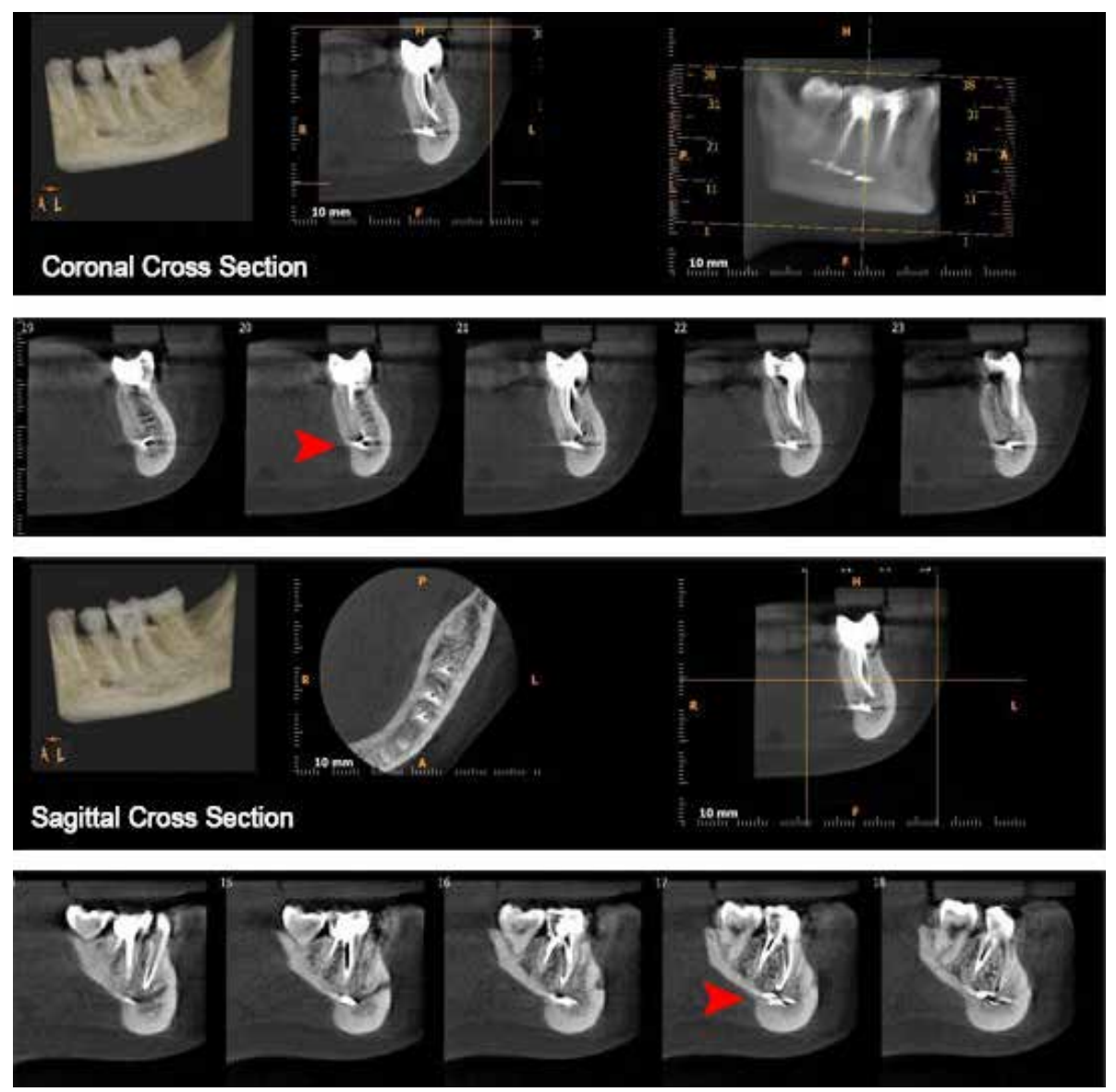

Fig. 2. Coronal and Sagittal cross sectional CBCT images (y. 2014).

Four routes were described regarding the extrusion of filling pastes and cements to the periapical zone: directly toward the mandibular canal, through a periapical vein, through lymphatic vessels, and toward soft tissues between bone and mucosal membrane. ${ }^{[17]}$ In this case, root canal sealer was extruded directly toward the mandibular canal.

Particular ingredients (i.e eugenol) and by products such as paraformaldehyde are known to be more neurotoxic. ${ }^{[3,4]}$ For example, AH26 (De Trey Fréres SA, Zurich, Switzerland) was a commonly used resin based root canal sealer and was known to release formaldehyde as a by-product. ${ }^{[18]}$ The successor; AH Plus (Dentsply DeTrey $\mathrm{GmbH}$, Konstaz, Germany), was found to release less amount of formaldehyde; however, one of its components, bisphenol A, was also reported as causing cytotoxic effects. ${ }^{[19]}$ What is more, the materials like gutta-percha, which is considered to be inert, or calcium hydroxide, which is considered to be a physiologically acceptable material, also showed nerve damage both in experimental studies and in clinical cases. ${ }^{[7,20,21]}$ Not only obturation and intracanal medicament materials, but also irrigation solutions like hypo- chlorite and etyhlenediamine tetraacedic acid were shown to cause chemical toxicity on nerve tissue. ${ }^{[7,12,20-22]}$ However, the type of the filling paste material and its features of present case report were unknown because contact with the previous dentist was unsuccessful.

Therefore it is crucial to confine whole procedure within the root canal; apply materials according to manufacturers instructions and choosing the appropriate techniques for the case not to damage the nerve tissue.

The literature review on treatment of overextension of endodontic obturation materials reveals that removal of the foreign material from the mandibular canal by sagittal osteotomy can be an effective treatment option. ${ }^{[23]}$ However, in this case surgical intervention was not preferred considering the long period of time following injury supposed to increase the risk of irreversible changes on nerve tissue $^{[23]}$ as well as additional trauma and unpredictable prognosis. Follow-up visits were scheduled.

A more recent literature review on treatment of inferior alveolar nerve damage due to endodontic paste penetration into the mandibular canal revealed that the daily administration of $150 \mathrm{mg}$ pregabalin, which is known as 
an anticonvulsant drug, with small doses of prednisone was reported to resolve paresthesia completely when prescribed for a period of one month beginning within three weeks following injury. ${ }^{[24,25]}$ This option was discussed but not preferred in the current case as she was referred more than one year after the injury.

\section{Conclusion}

Damage to the inferior alveolar nerve is a relatively rare complication in dental practice. However, it may have long-lasting consequences such as paresthesia presented in the current case. This case report discusses the treatment options for nerve injury due to endodontic treatment as well as stressing the necessity of absolute care to avoid apical extrusion especially when root apices are in close proximity to the mandibular canal.

Conflict of interest: None declared.

\section{References}

1. González-Martín M, Torres-Lagares D, Gutiérrez-Pérez JL, Segura-Egea JJ. Inferior alveolar nerve paresthesia after overfilling of endodontic sealer into the mandibular canal. J Endod 2010;36:1419-21. Crossref

2. Vertucci FJ, Haddix JE. Tooth morphology and access cavity preparation. In: Cohen S HK, ed. Pathways of the pulp 10th ed. St. Louis: Mosby; 2011, p. 136-222. Crossref

3. Brodin P, Røed A, Aars H, Orstavik D. Neurotoxic effects of root filling materials on rat phrenic nerve in vitro.J Dent Res 1982;61:1020-3. Crossref

4. Serper A, Uçer O, Onur R, Etikan I. Comparative neurotoxic effects of root canal filling materials on rat sciatic nerve. J Endod 1998;24:592-4. Crossref

5. Peters OA, Peters CI. Cleaning and shaping of the root canal system. In: Cohen S HK, ed. Pathways of the pulp, 10th ed. St. Louis: Mosby; 2011. p. 283-348. Crossref

6. Morse DR. Infection-related mental and inferior alveolar nerve paresthesia: literature review and presentation of two cases. J Endod 1997;23:457-60.

7. Ahlgren FK, Johannessen AC, Hellem S. Displaced calcium hydroxide paste causing inferior alveolar nerve paraesthesia: report of a case. Oral Surg Oral Med Oral Pathol Oral Radiol Endod 2003;96:734-7. Crossref

8. Gallas-Torreira MM, Reboiras-López MD, García-García A, Gándara-Rey J. Mandibular nerve paresthesia caused by endodontic treatment. Med Oral 2003;8:299-303.

9. Poveda R, Bagán JV, Fernández JM, Sanchis JM. Mental nerve paresthesia associated with endodontic paste within the mandibular canal: report of a case. Oral Surg Oral Med Oral Pathol Oral Radiol Endod 2006;102:46-9. Crossref

10. Froes FG, Miranda AM, Abad Eda C, Riche FN, Pires FR. Non-surgical management of paraesthesia and pain associ- ated with endodontic sealer extrusion into the mandibular canal. Aust Endod J 2009;35:183-6. Crossref

11. Köseoğlu BG, Tanrikulu S, Sübay RK, Sencer S. Anesthesia following overfilling of a root canal sealer into the mandibular canal: a case report. Oral Surg Oral Med Oral Pathol Oral Radiol Endod 2006;101:803-6. Crossref

12. Brooks JK, Kleinman JW. Retrieval of extensive guttapercha extruded into the maxillary sinus: use of 3-dimensional cone-beam computed tomography. J Endod 2013;39:1189-93, Crossref

13. Tilotta-Yasukawa F, Millot S, El Haddioui A, Bravetti P, Gaudy JF. Labiomandibular paresthesia caused by endodontic treatment: an anatomic and clinical study. Oral Surg Oral Med Oral Pathol Oral Radiol Endod 2006;102:47-59. Crossref

14. Alves FR, Coutinho MS, Gonçalves LS. Endodontic-related facial paresthesia: systematic review. J Can Dent Assoc $2014 ; 80 \div 13$.

15. Denio D, Torabinejad M, Bakland LK. Anatomical relationship of the mandibular canal to its surrounding structures in mature mandibles. J Endod 1992;18:161-5. Crossref

16. Neaverth EJ. Disabling complications following inadvertent overextension of a root canal filling material. J Endod 1989;15:135-9. Crossref

17. Alantar A, Tarragano H, Lefèvre B. Extrusion of endodontic filling material into the insertions of the mylohyoid muscle. A case report. Oral Surg Oral Med Oral Pathol 1994;78:646-9. Crossref

18. Leonardo MR, Bezerra da Silva LA, Filho MT, Santana da Silva R. Release of formaldehyde by 4 endodontic sealers. Oral Surg Oral Med Oral Pathol Oral Radiol Endod 1999;88:221-5. Crossref

19. Segura JJ, Jiménez-Rubio A, Pulgar R, Olea N, Guerrero $\mathrm{JM}$, Calvo JR. In vitro effect of the resin component bisphenol A on substrate adherence capacity of macrophages. J Endod 1999;25:341-4, Crossref

20. Boiesen J, Brodin P. Neurotoxic effect of two root canal sealers with calcium hydroxide on rat phrenic nerve in vitro. Endod Dent Traumatol 1991;7:242-5. Crossref

21. Blanas N, Kienle F, Sándor GK. Inferior alveolar nerve injury caused by thermoplastic gutta-percha overextension. J Can Dent Assoc 2004;70:384-7.

22. Witton R, Brennan PA. Severe tissue damage and neurological deficit following extravasation of sodium hypochlorite solution during routine endodontic treatment. Br Dent J 2005;198:749-50.

23. Scolozzi P, Lombardi T, Jaques B. Successful inferior alveolar nerve decompression for dysesthesia following endodontic treatment: report of 4 cases treated by mandibular sagittal osteotomy. Oral Surg Oral Med Oral Pathol Oral Radiol Endod 2004;97:625-31. Crossref

24. López-López J, Estrugo-Devesa A, Jané-Salas E, SeguraEgea JJ. Inferior alveolar nerve injury resulting from over- 
extension of an endodontic sealer: non-surgical management using the GABA analogue pregabalin. Int Endod J 2012;45:98-104. Crosssef

25. Alonso-Ezpeleta O, Martín PJ, López-López J, Castella-
nos-Cosano L, Martín-González J, Segura-Egea JJ. Pregabalin in the treatment of inferior alveolar nerve paraesthesia following overfilling of endodontic sealer. J Clin Exp Dent 2014;6:197-202. Crossref 